\title{
Tidelines: Creative Vision, Ecology and the Tropics
}

\author{
Robyn Glade-Wright
}

James Cook University

\begin{abstract}
On a sunny, calm day in the tropics, waves wash ashore plastic bottles, discarded thongs and sparkling red shards from broken car taillights, littering the tideline. The appeal of the tropics, imagined as a pristine verdant paradise replete with exotic plants and enigmatic animals, belies the impact of human activity on the region. Works of art, however, can reveal this ecological change, offering new ways of comprehending our place in the tropics. The capacity of artists to address these changes in a way that generates reflective understanding is examined in this paper. Both the author's works of art and those of other artists in the tropical region are analyzed in terms of their aesthetic properties. These findings may assist artists who endeavor to present new ways of imaging change in the ecology of the tropics.
\end{abstract}

Key Words: art, ecology, environment.

\section{Introduction}

$\mathrm{T}$ he slogan promoted in advertising materials for several educational institutions in the tropical region of Far North Queensland in Australia is "Study in Paradise". Picture perfect images of exotic palm fringed beaches with golden sand and turquoise seas have long tantalized those who live in cooler climates with the promise of warmth, relaxation and an escape. However, the 'paradise' of the tropics is threatened and retreating. Plastic bottles and discarded thongs that have been washed ashore interrupt the pleasure of a morning walk on the beach. A sparkling red shard from a broken car taillight, washed up on the tidelines looks for a moment like a precious shell or piece of coral. This delight is momentary and quickly turns to disappointment, as the imagined joy of the natural environment is tarnished by debris from our society.

Further out to sea, an additional impact of human activity is apparent in the loss of twenty-eight percent of the coral cover of the Great Barrier Reef over the past three decades (De'ath, Fabricius, Sweatman, \& Puotinen, 2012). Emissions from the past have overloaded the atmosphere at a rate that has outstripped the earth's ability to reabsorb the excess (Ortiz, Bozec, Wolf, Doropoulos, \& Mumby, 2014). Six to thirtyfive thousand tons of plastic debris is floating in the ocean, poisoning marine organisms and entering the food web (Duarte, 2014). Of the estimated thirty thousand plant species in the tropics, half are at risk of extinction (Pimm \& Joppa, 2015, p. 170). The extinction rate is 1,000 times higher than it was before human activities started to have a significant global impact on earth's ecosystems (ibid).

People have become the primary contributors to extinctions (De Vos, Joppa, Gittleman, Stephens, \& Pimm, 2014), while anthropocentric climate change has 
marked a shift in the natural world (Corner, Parkhill, Pidgeon, \& Vaughn, 2012, p. 940). Global systems are now "fundamentally linked to choices made by human societies" (ibid.). The term, 'climate change' has evolved from a technical term to a political issue and "one of the defining challenges of the $21^{\text {st }}$ century" (ibid.). In this paper, the shared responsibility of managing the ecology of this small planet is addressed in the works of art of international and local artists.

Practice-led research informs this paper as it enables artists to consider the theoretical and philosophical position of their work. Theories work to inform practice and practice informs theory, therefore, creating a praxis that can generate new ways of conceiving, creating and explaining contemporary works of art (Danto, 2013). The paper reviews theories of art and contemporary works of art that mainly relate to the field on environmental art. This is followed by reflections of the author's creative works.

\section{Theoretical Context}

Highly recognized artists have a talent for creating works of art that enrich our life by enabling us to form a greater understanding of our experiences of life, therefore, contributing in a broad sense to the enlargement of knowledge (Graham, 2005). The value of the contemporary art resides in its cognitive significance and the sensuous manner in which meaning is conveyed (Danto, 2013). Highly regarded works of art are recognized for their veracity, persuasiveness and imaginative significance. Imaginative significance can be viewed as the degree to which the work moves people, eliciting deliberation, new understanding and creating lasting memories. The words, 'illuminating,' 'insightful' and 'profound' convey the meaning of the term 'imaginative significance'. The arts are valued for their imaginative significance and capacity to elicit reflection and to reveal original and useful perceptions.

Artists have the capacity for insight and the ability to communicate these ways of seeing in the fabric of the work of art by symbolic means. Because works of art are symbolic unique original entities, they stand apart from the real world. For example, Duchamp's Fountain (1917) is a urinal purchased from a hardware store, at the time it was exhibited. In the hardware store it had a different symbolic value to the one it had in the gallery. In the context of a gallery, the signed and upturned urinal was loaded with symbolic meaning. Fountain asked the question, "Is this art?". It is via symbolic means that contemporary works of art communicate the aim of the artist (Danto, 2013).

Significant works of art can trigger a cognitive journey involving an experience of pleasure, beauty, or emotion. Our reactions to works of art are mediated by our beliefs and our longings (Kirwan, 1999). In many instances, the trigger for an artist's work may be a known fact that is established in fields such as the physical or social sciences (Graham, 2005). Artists can represent facts in a symbolic manner that is provocative and this may contribute to social change. A poignant example of an artist whose aim is social change is Huang, whose work, Crossing the Tide, was exhibited at the Tuvalu Pavilion, 2015 Venice Biennale.

Crossing the Tide, shown in Figure 1, consists of a turquoise pool, crossed by two paths. The paths submerge slightly, allowing water to spill onto the path as audience 
members walk between the pools. This disconcerting and sinking feeling connects the audience with the predicament of the people of the island nation of Tuvalu, located in the Pacific Ocean, who are at risk of inundation by rising sea levels (Lin, Ho, Cheng, \& Liang, 2015). Sea levels are predicted to rise by between $0.09-0.88$ metre by the year 2100 (ibid.). Therefore, Crossing the Tide poignantly awakens us to the rising tide in Tuvalu and reminds us that all current coastlines are temporary.

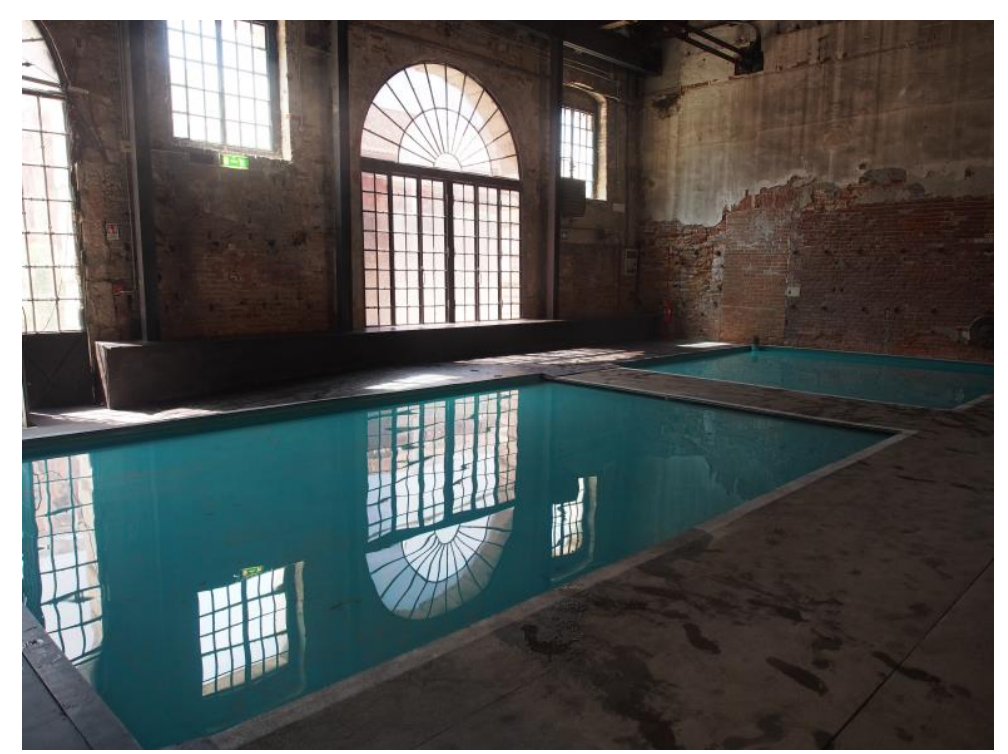

Figure 1. Vincent Huang. Crossing the Tide 2015 Pool, path, mist.

In the tropical region, Cairn artist Barbara Dover eloquently expresses concern about marine life in the works Missing \#1 and Missing \#2 (2015), shown in Figure 2 and Figure 3. In these pieces, Dover has cut out images of sharks, dolphins and turtles from a map depicting the Cairns region in which these marine animals lived and were once abundant. Missing \#1 and Missing \#2 suggest an oceanic world devoid of these creatures and one in which their seemingly lifeless bodies appear to have fallen over a precipice, dangling beyond the bottom of the world and edge of the map. Dover states:

This work reflects my anxiety about the pressures on the Great Barrier Reef that fringes Cairns, where I live. While tourists come to enjoy its beauty, I am concerned about the increasing threats to the reef and the marine animals, including sharks and turtles, such as climate change, declining water quality, coastal development, rising sea levels, illegal fishing and marine debris, which are endangering the reef and its inhabitants. (2015) 


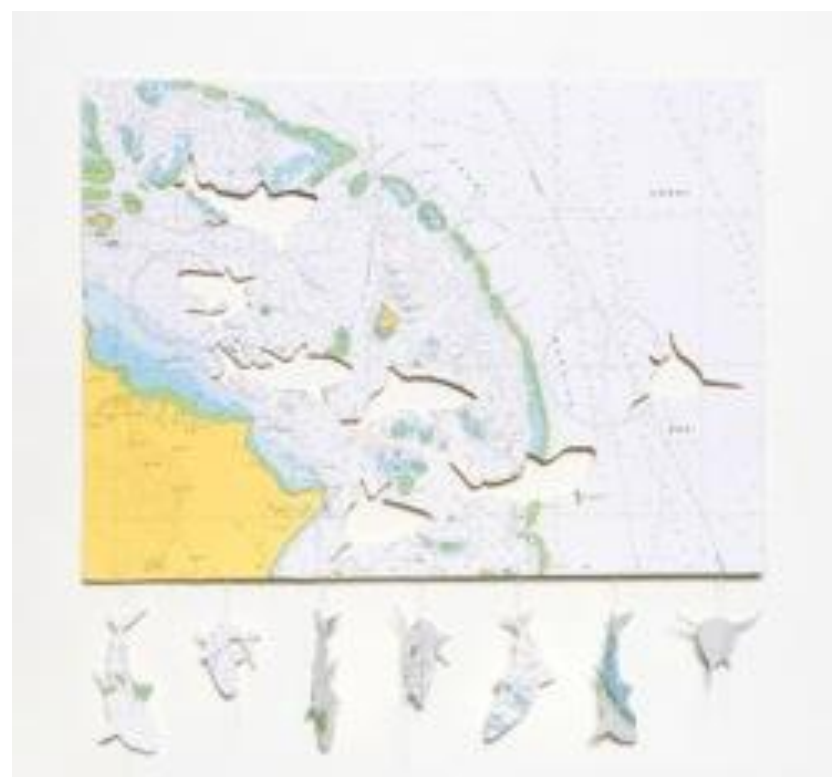

Figure 2. Barbara Dover Missing \#1 2015 Paper, collage and thread h $74 \mathrm{xw} 76 \mathrm{~cm}$

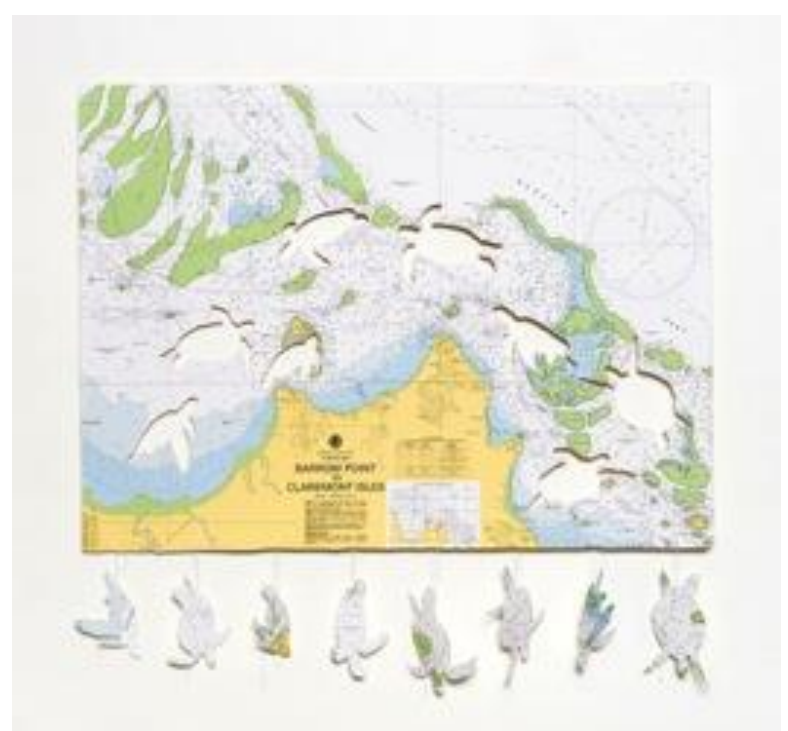

Figure 3. Barbara Dover Missing \#2 2015 Paper, collage and thread h 74 x w $76 \mathrm{~cm}$

The works of Huang and Dover, amongst others, use known facts and represent them in symbolic form. They do this in a memorable manner that has an emotional and cognitive impact. The works remind us of situations that we may prefer to ignore, such as the rise in sea levels and the demise of animal populations. Therefore, artists undertake their labours not only on their own behalf but also on behalf of the wider community (Graham, 2005).

In many instances, the trigger for an artist's work may be a known fact established in the physical or social sciences, however, in other works of art, the facts are presented in a make -believe manner (Graham, 2005). For example, in Missing \#1 and Missing $\# 2$, the known facts regarding the demise in turtle, shark and dolphin populations are 
represented in a manner that involves fiction. Turtles, sharks and dolphins have not been cut out of the sea; however, alarmingly, this might be the case. The play of art involves a fantasy realm that is not real, but it relates to real life situations and hence, it can enrich our understanding of experiences (ibid.).

\section{Fictitious Space and the Possibility of Truth}

The theorist, Kendal Walton argues that art is a "prop in a game of make-believe" (1990, p. 68) and in a similar vein, the writer and painter, Julian Bell (2013) contends that, "The whole zone called 'art' is in many senses a fictive space" (https://www.tate.org.uk/art/research-publications/the-sublime/julian-bellcontemporary-art-and-the-sublime-r1108499). Works of art may be fictitious in both the phase of their production and reception (Danto, 2013). The 'fictitious' title is an honorific title as works of art are original works of an artist's imagination.

A poignant example of art as a prop in a game of make-believe is And No Bird Sings, shown in Figures 4, 5 and 6, by Barbara Dover (2014). And No Bird Sings suggests a world where birds and their calls have vanished. The work presents a poetic vision that implies a potentially chilling future world and a diminished existence. It is a potent reminder, lest we forget our responsibility to the animals with whom we share the planet. The idea that birds and their calls are absent indicates how an artist's insight and imagination can evoke a unique and make-believe reality. It is this capacity for artists to imagine and communicate an original reality, and to direct attention to aspects of a subject or situation that others have not noticed that distinguishes significant art from less revered works of art (Graham, 2005).

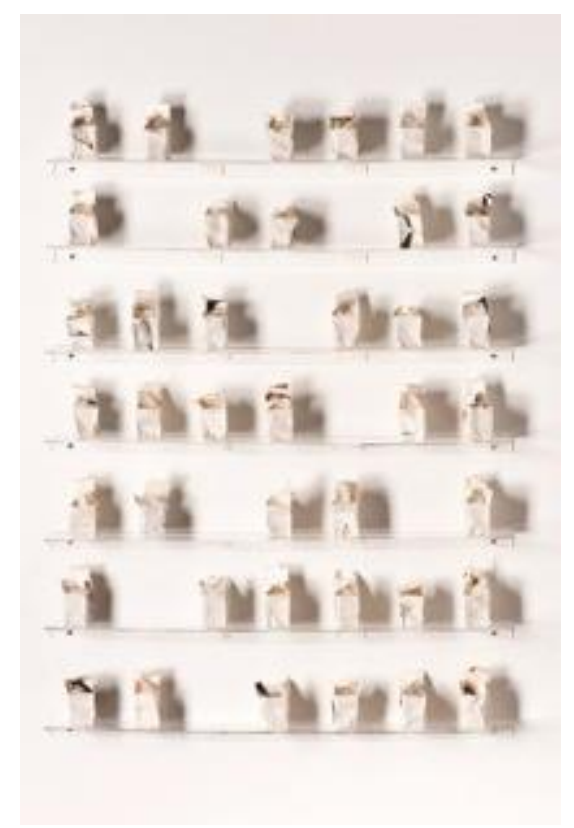

Figure 4. Barbara Dover And No Bird Sing 2014 Deconstructed book, found feathers, acrylic

h 135 x w $100 \mathrm{~cm}$

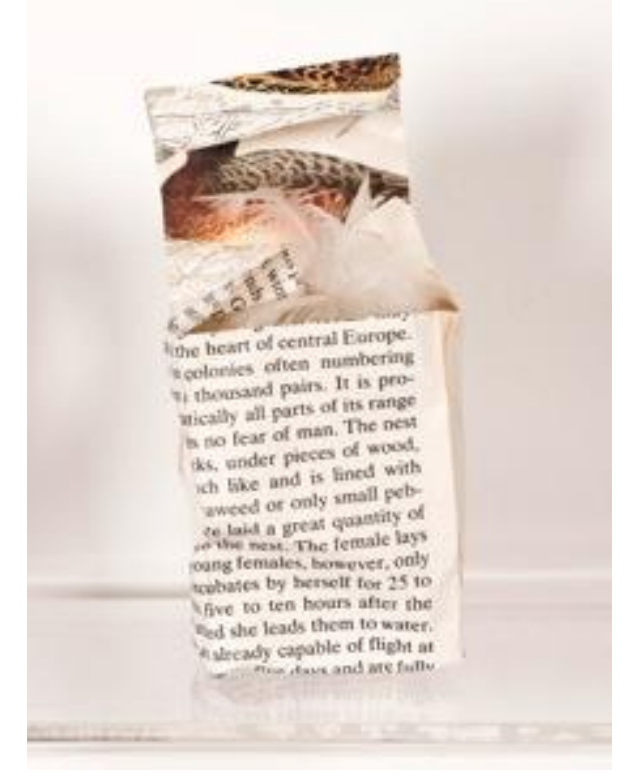

Figure 5. Barbara Dover And No Bird Sings 2014

Deconstructed book, found feathers, acrylic

h 135 x w $100 \mathrm{~cm}$ 


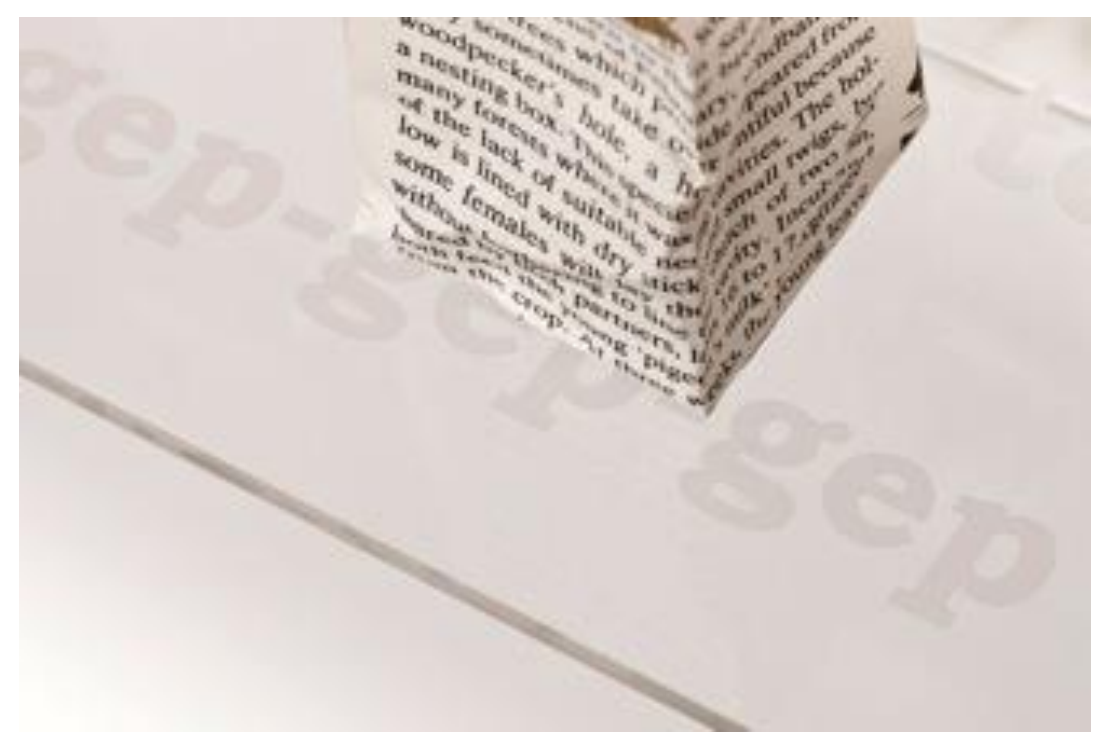

Figure 6. Barbara Dover And No Bird Sings (detail) 2014 Deconstructed book, found feathers, acrylic h 135 x w $100 \mathrm{~cm}$

The idea that works of art are works of imagination and props in a game of "makebelieve" is demonstrated if we consider portraits. Our judgment of whether a portrait is good or poor is not dependent on knowing how closely the portrait resembles the person it represents. We can tell whether a portrait is a good portrait even when the portrait was painted prior to the advent of photography, without knowing what the person looked like. For example, Rembrandt van Rijn's Man With the Golden Helmet c. 1650 is widely regarded as a fine portrait, however we do not know if it resembles the sitter. Man With the Golden Helmet revels a great deal about the human condition of the depicted man. We can judge if a portrait is a valuable and appealing work of art, by the manner in which it provides aesthetic reward and/or reveals aspects of life (Graham, 2005).

A further case to consider is photographic portraiture. The subjects in portraits can be said to be available in the real world. However, a photographer composes, lights and reproduces an image in a specific manner to reveal nuances that create the power of the image. For example, Dorothea Lange's well-known portrait, Migrant Mother (1936) is a haunting image, and one that gains much of its intensity due to the composition and black and white form. It is Lange's insight and her capacity for communication in an engaging, sensuous form that has coalesced to create a culturally significant image.

Images of people are not real, but symbolic representations of people and therefore, works of art cannot be tested by comparison to real world subjects. Artists direct our attention in their works, however, this can hardly be said to be in the direction of reality, but instead, to an aesthetic experience and to an understanding of experience (Graham, 2005).

The fictitious nature of art presents make-believe realms where people can gain the value of experience without the usual cost (Walton, 1990). People who view artworks or attend performances may gain understanding of life without the time and effort 
associated with experiencing a real life situation. We do not need to live through a power struggle if we attend a performance that provides us with a vision of this kind of experience (Graham, 2005). Works of art stand apart from real life, however, as they relate to life, they may enrich it. Despite their fictitious nature, works of art "have the possibility of truth" (Danto, 2013, p. 155).

\section{Aesthetics and cognition}

Danto wrote that, "Much of contemporary art is hardly aesthetic at all but it has instead the power of meaning" (Danto, 2013, p. 155). An example of work that privileges meaning over aesthetics includes Oscar Murillo's ongoing project in which students, aged ten to sixteen, in twenty-one countries, were given canvases for their school desks. The completed drawings, shipped to Murillo, demonstrate markedly different world-views. "The ones from Argentina had hearts and hashtags; the ones from Kenya had guns and helicopters; and the ones from Israel had rap and graffiti" (http://www.complex.com/style/2015/05/venice-biennale-2015). These drawings were shown as a work of art at the 2015 Venice Biennale, raising questions about the nature of contemporary arts practice. For example, can a collection of children's drawings be contemporary art? Therefore, this work communicates through the power of meaning, in a manner that Danto might claim is "hardly aesthetic" (Danto, 2013, p. $155)$.

Christian Phillip Muller's The New World (2012) is another work of art that privileges meaning over aesthetics. In this piece, audience members are invited to walk across three pontoons. The pontoons have chard growing in them and you can pick and eat the chard. The pontoons move as you cross and it is precarious as you climb and descend the steps that join the three pontoons. The New World is an eloquent metaphor for the precarious supply of food on this small planet.

In contrast to the work of Murillo and Muller, where the dominant feature of the work is the concept and aesthetic considerations are less evident, in works of art such as And No Bird Sings these elements are in equilibrium. In other culturally significant works of art, aesthetics can be the dominant member of the pair. For example, paintings by Cairns artist Jacqueline Scotcher exhibit a sensuous and tactile aesthetic. Ideas hover in paintings such Rising Water (2012), shown in Figure 7. There is an underlying current in these paintings, made memorable by a highly refined aesthetic. The sophisticated and beautiful use of colour in Rising Water (2012) and enticing texture of Trinity Beach Morning Sunday (2012) shown in Figure 8, make these paintings memorable cultural artefacts. 


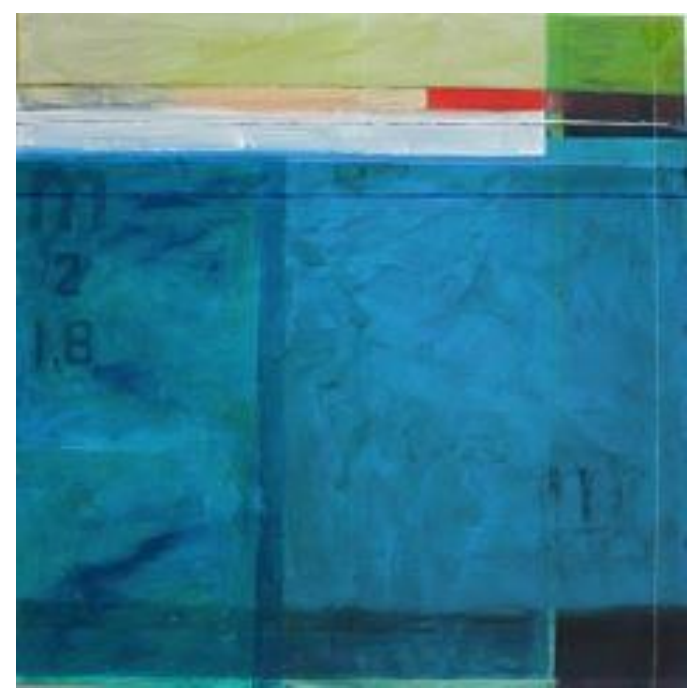

Figure 7. Jacqueline Schotcher

Rising Water 2012

synthetic polymers on canvas, h $120 \mathrm{x} \mathrm{w}$ $120 \mathrm{~cm}$

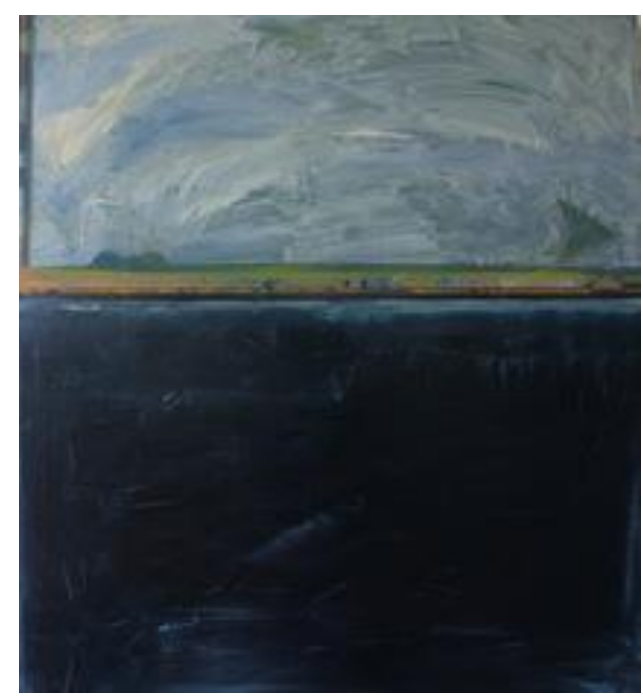

Figure 8. Jacqueline Schotcher

Trinity Beach Morning Sunday 2012 synthetic polymers on canvas, h $110 \mathrm{x} \mathrm{w}$ $90 \mathrm{~cm}$

\section{Authors Works}

Walton's idea of art being a prop in a game of make-believe is informative in the authors' work where both cognitive and aesthetic considerations are at play (1993). In Exodus (2014), shown in Figure 9, a representation of long boat composed of bleached coral is suspended and sways gently as it ferries its cargo of dead coral to an unmarked grave. The piece commemorates the loss of coral in the Great Barrier Reef. The demise of the coral has occurred as fertilizers used in agriculture have been washed into the sea, spurring outbreaks of crown of thorns starfish. The starfish feed on the coral decimating large areas of the reef (De'ath et al., 2012). Increased sea temperatures due to global warming kill the tiny algae that provide nutrients for the coral and, starved of food, the coral die and the reef bleaches (ibid.). Climate change has caused an increase in the frequency and severity of cyclones (ibid.). Cyclones destroy swaths of reef in their devastating path. Collectively these factors have led to the demise of the reef. 


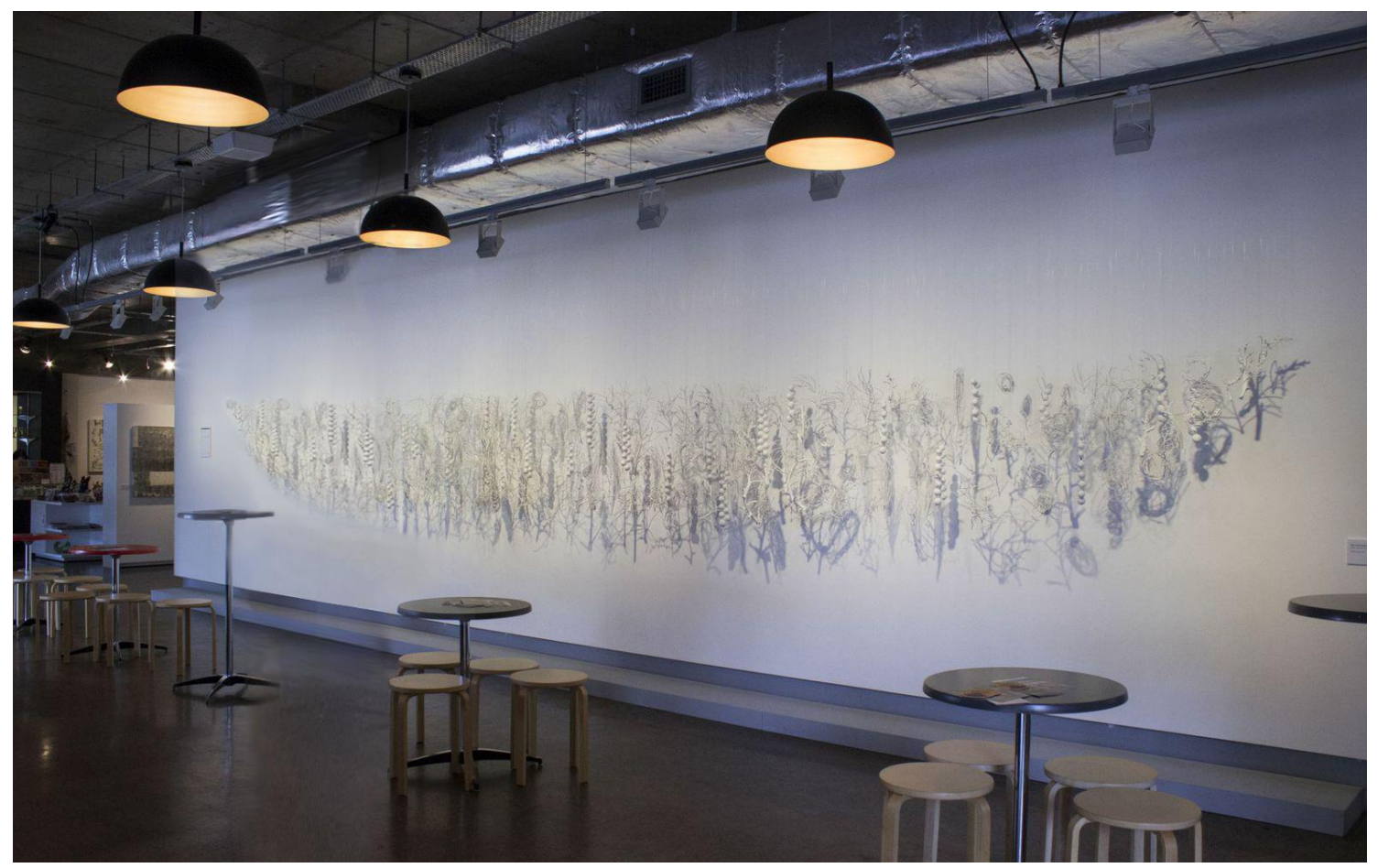

Figure 9. Robyn Glade-Wright Exodus 2014.

Vegetation, beads, acrylic paint. w 990 x h 88 x d $20 \mathrm{~cm}$.

Exodus recalls Arnold Bocklin's painting Isle of the Dead (1880), where a white, shrouded figure is carried to a grave. In Isle of the Dead and Exodus the lifeless bodies are ferried away. The cognitive nature of the work is coupled with a subversive beauty. While beauty is bound up in meaningful relationships, the beauty of the coral has vanished in Exodus. The work attempts to create a chilling realization of the beauty we have lost as the coral silently dissolves and vanishes.

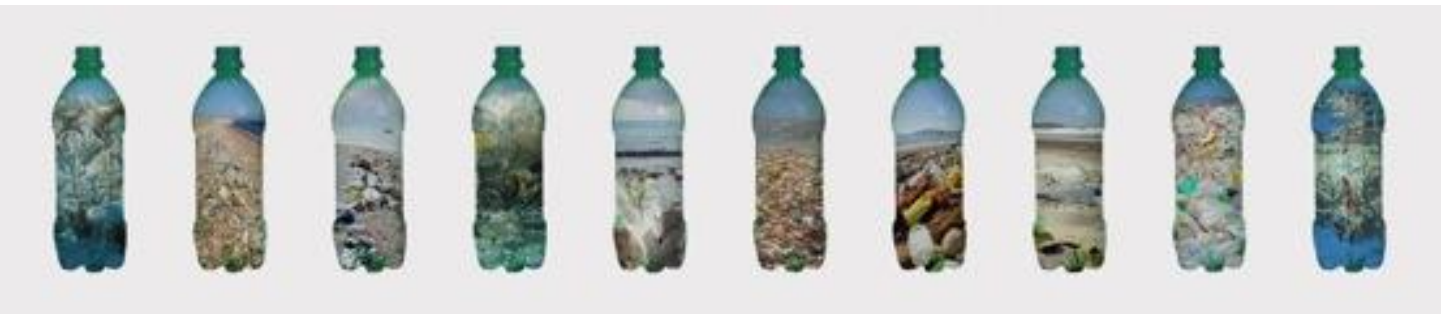

Figure 10. Robyn Glade-Wright Ten Green Bottles 2015

Digital Image h 42 x w $220 \mathrm{~cm}$

Ten Green Bottles (2015) is another example work of art by the author, depicting the demise of the marine environment. Ten Green Bottles, shown in Figure 10, depicts ten clear plastic drinking bottles that appear to contain plastic waste, washed up on the shoreline or floating in the sea in gyres of plastic debris. These bottles do not provide a source of life-giving water, but instead, they contain water contaminated with plastic waste. Plastic drinking bottles add to the plastic waste that pollutes our environment. The title, Ten Green Bottles, recalls the children's rhyming song of the same name that is associated with the innocence of childhood. Innocence is lost in relation to the scenes depicted in the bottles, where waste dumped in the oceans and waterways is far from an innocent act. The work aims to deliver an uncomfortable 'message in a bottle'. 


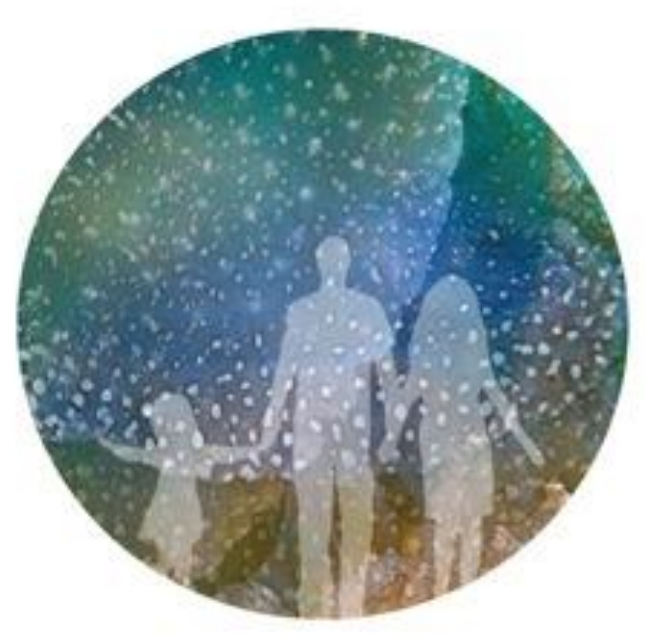

Figure 11. Robyn Glade-Wright Overload 2015

Seeds paint bamboo stick h 240 x w $240 \mathrm{~cm}$

Overload shown in Figure 11, is a work of art that will be shown in the Cairns Regional Gallery in November 2015. The work consists of 800 painted seeds that are the size of golf balls or smaller. These round forms are coated with fine rubber to create an ambiguous surface. Small sticks connect the round forms to emulate a diagram of an atom and to suggests the invisible atoms of pollution that are present in the air we breathe. The balls surround a family and sweep through their bodies suggesting the effects of emissions on our physiology. Overload attempts to direct our attention to the emission we cannot see. The work uses a beautiful form to capture attention and potentially generate reflection. It is a subversive use of beauty to draw attention to a message based on known facts in a make-believe form.

\section{Conclusion}

Artists can use extant knowledge to create make-believe works that enable others to come to a greater understanding of experience. Artists possess a special capacity of insight along with the imagination and ability to communicate their insights in a sensuous form and this is what gives art its persuasive power (Armstrong, 2004). In the works of art created by Dover, Huang, Muller, Scotcher and Glade-Wright, the effects of the anthropocene are represented in a fictitious, aesthetic and symbolic manner to highlight the great lie that occurs when we imagine that we are not responsible for 'making and changing nature'. When a small shard from a red car taillight is washed up on the tideline, and appears to be a jewel, our world has changed in ways that may not be sustainable. 


\section{Works Cited}

Armstrong, J. (2004). The Secret Power of Beauty. London: Allen Lane.

Bell, J. (2013). 'Contemporary Art and the Sublime', in Nigel Llewellyn and Christine Riding (eds.), The Art of the Sublime, Tate Research Publication. Retrieved from: https://www.tate.org.uk/art/research-publications/thesublime/julian-bell-contemporary-art-and-the-sublime-r1108499

Corner, A., Parkhill, K., Pidgeon, N., \& Vaughn, N.E. (2013). Messing with nature? Exploring public perceptions of geoengineering in the UK. Global Environmental Change, 23, 938-947.

Danto, A.C. (2013). What Art Is. New Haven, CT: Yale University Press.

De'ath, G., Fabricius, K.E., Sweatman, H., \& Puotinen, M. (2012). The 27 - year decline of coral cover on the Great Barrier Reef and its causes. Proceedings of the National Academy of the United States of America, 44,17995-17999.

De Vos, J.M., Joppa, L.N., Gittleman, J.L., Stephens, P.R., \& Pimm, S.L. (2014). Estimating the normal background rate of species extinction. Conservation Biology, 29(2), 452-62.

Dover, B. (2015). "Re: Missing \#1 and Missing \#2” Message to author. 10 Sept. 2015. E-mail.

Duarte, C. (2014). Where is the oceans' missing plastic?" ECOS Science for Sustainability 199.

Graham, G. (2005). Philosophy of the Arts. London: Routledge.

Kirwan, J. (1999). Beauty. Manchester: Manchester University Press.

Lin, C.C., Ho, C.R., Cheng, Y.H., \& Liang, S.J. (2015). Regional Flooding Induced by Tide and Warm Water Effects in Tuvalu. Ocean. Science, 26(2), 213-218.

Ortiz, J.C., Bozec, Y.M., Wolf, N.H., Doropoulos, C., \& Mumby, P.J. (2014). Global disparity in the ecological benefits of reducing carbon emissions for coral reefs. Nature Climate Change, 4, 1090-1094.

Pimm, S.L., \& Joppa, L.N. (2015). How Many Plant Species are There, Where are They, and at What Rate are They Going Extinct? Annals of the Missouri Botanical Garden, 100(3), 170-176.

Walton, K. (1990). Mimesis as Make-Believe: On Foundations of the Representational. Cambridge: Oxford University Press. 